\title{
High-Level Expression of Golsyn/Syntabulin in Glandular Epithelium and its Role in the Secretory Process
}

\author{
Ryosuke Oda $^{1}$, Eishi Funakoshi*, ${ }^{1}$, Kiyokazu Ozaki ${ }^{2}$, Kiyokazu Ogita $^{3}$, Nobuyoshi Shimizu ${ }^{4}$ and \\ Fumiaki Ito ${ }^{1}$
}

Departments of ${ }^{1}$ Biochemistry, ${ }^{2}$ Pathology, and ${ }^{3}$ Pharmacology, Faculty of Pharmaceutical Sciences, Setsunan University, 45-1 Nagaotoge-cho, Hirakata, Osaka 573-0101, Japan; and ${ }^{4}$ Advanced Research Center for Genome Super Power, Keio University, 2 Okubo, Tsukuba, Ibaraki 300-2611, Japan

\begin{abstract}
We recently identified a novel gene, named GOLSYN/Syntabulin, on human chromosome 8q23.2. In neurons, GOLSYN/Syntabulin functions as a molecule linking syntaxin 1-containing vesicles to kinesin, and thus plays an essential role in the transport of vesicles and mitochondria along neuronal processes. GOLSYN/Syntabulin is ubiquitously expressed in most peripheral tissues besides various brain regions. However, the physiological function in the periphery remains unknown. In this study, we determined the expression of Golsyn/Syntabulin in various mouse organs by immunohistochemical analysis using anti-GOLSYN antibody. Golsyn/Syntabulin was abundantly expressed in the glandular epithelium in the various peripheral organs examined: In exocrine glands, it was expressed in secretory cells, such as chief cells in the stomach and pancreatic acinar cells; and in endocrine glands, it was detected in pancreatic islet cells, which are endocrine cells that produce and release hormones including insulin and glucagon. The expression of Golsyn/Syntabulin was drastically decreased in pancreas and liver by fasting, but it was not affected in the testis, which has no secretory glands for food digestion. Subsequent refeeding recovered Golsyn/Syntabulin expression in pancreas and liver tissues to almost control levels, indicating the association of its expression with food intake. Further, administration of gastrin or pilocarpine led to a remarkable increase in the expression level of Golsyn/Syntabulin in the pancreas. Since food intake, gastrin, and pilocarpine are known to stimulate the secretion of pancreatic enzymes, Golsyn/Syntabulin may play an important role in the secretion process, including transport of secretory vesicles and/or exocytosis, in glandular epithelium.
\end{abstract}

Keywords: GOLSYN, glandular epithelium, secretory cells, pancreas, zymogen granule, vesicular transport.

\section{INTRODUCTION}

Vesicular transport is an essential process for cellular organization and functions including cell division, cell motility, formation of cellular polarity, and release of neurotransmitters and hormones [1-3]. Vesicles carry membrane components and soluble molecules referred to as cargo. The delivery of cargo via vesicular transport to their correct destination is ensured by complex molecular machinery [4]. Several families of proteins, such as Rab GTPase, SNARE, and motor protein, are essential components in guiding vesicular transport [5-7]. Further, adaptor proteins that act as a linker between motor proteins and vesicles have been identified [810]. Functional and structural characterization of these proteins contributes to our understanding of the highly organized machinery required for intracellular vesicle transport.

Earlier we identified a novel gene encoding a transmembrane protein with a coiled-coil domain and determined its location to be on human chromosome 8q23.2, to which primary open-angle glaucoma has been mapped. We named this gene [18], because its product is localized to the Golgi apparatus in epithelial cells and is homologous to syntaphilin, a protein involved in guiding vesicular transport

*Address correspondence to this author at the Department of Biochemistry, Faculty of Pharmaceutical Sciences, Setsunan University, Osaka 573-0101, Japan; Tel: +81-72-866-3117; Fax: +81-72-866-3117;

E-mail: funakos@pharm.setsunan.ac.jp
$[11,12]$. On the other hand, $\mathrm{Su}$ et al. isolated a gene from human fetal brain cDNA library by using the degenerate PCR technique [13]. This gene was named Syntabulin and identical to human GOLSYN. In rat hippocampal neurons, Syntabulin bound to both syntaxin 1 and the kinesin heavy chain and functioned as a molecule linking both proteins, enabling transport of vesicles containing syntaxin 1 to nerve terminals $[13,14]$. Further, Syntabulin was shown to be involved in intracellular transport of mitochondria in neurons [15], indicating that Syntabulin plays a crucial role in the transport of vesicles and organelles in these cells.

Later we isolated m-Golsyn, the mouse ortholog of human GOLSYN, and mapped it to the region on mouse chromosome 15B3.2 syntenic with human chromosome $8 \mathrm{q} 23$. mGolsyn was expressed not only in neuronal cells but also in various organs and cell lines including epithelial cells [16, 17]. Golsyn/Syntabulin, therefore, may be involved in vesicular transport in various organs other than the brain.

In this present study, we examined the expression of Golsyn/Syntabulin in various mouse organs. Golsyn/Syntabulin was expressed mainly in epithelial cells, being abundantly expressed in the glandular epithelium of various organs. In pancreas and liver, fasting caused a marked decrease in Golsyn/Syntabulin expression, and refeeding after fasting recovered its expression. Further, gastrin injection or pilocarpine administration, both of which stimulate secretion of pancreatic enzymes, led to a remarkable increase in the Gol- 
syn/Syntabulin level in the pancreas. These findings indicate that the expression level of Golsyn/Syntabulin is closely associated with the secretory process, suggesting that this molecule is an important component in guiding vesicular transport.

\section{MATERIALS AND METHODOLOGY}

\subsection{Reagents}

The following materials were purchased from the sources indicated: pilocarpine and gastrin from Sigma Chemical Co. (Saint Louis, MO); Histofine from Nichirei Co. (Tokyo, Japan); and Vectastain ABC kit and biotinylated anti-rabbit IgG antibody from Vector Laboratories Inc. (Burlingame, CA). Sources of other materials are given in the text.

\subsection{Antibodies}

Rabbit anti-GOLSYN antibody was generated as described previously [18]. The following antibodies were purchased from the sources indicated: anti- $\beta$-actin antibody from Abcam Ltd. (Cambridge, UK); horseradish peroxidaseconjugated, swine anti-rabbit immunoglobulins from Dako Cytomation (Carointeria, CA); anti-mouse Ig, peroxidaselinked species-specific whole antibody from Amersham Biosciences (Piscataway, NJ).

\subsection{Animals and Treatment with Gastrin and Pilo- carpine}

Adult male ddY mice weighing 25 to $30 \mathrm{~g}$ (Japan SLC, Hamamatsu, Japan) were housed in metallic breeding cages in a room with a light-dark cycle of 12 hours/12 hours and humidity of $55 \%$ at $25^{\circ} \mathrm{C}$, with free access to food and water for at least 2 days before use. In the fasting group, the mice were housed with free access to only water for 24 hours. In the refeeding group, the animals were housed with free access to both food and water for 24 hours after the fasting period. For administration of gastrin, the mice were injected subcutaneously with $1 \mathrm{mg} / \mathrm{kg}$ of gastrin at 24 hours after fasting. For pilocarpine administration, other mice, housed with free access to food and water, were injected intraperitoneally with $66 \mathrm{mg} / \mathrm{kg}$ of pilocarpine and had free access to food and water until decapitation.

\subsection{Preparation of Various Mouse Organs}

The study protocol was approved by the Committee for Ethical Use of Experimental Animals at Setsunan University. All efforts were made to minimize animal suffering, to reduce the number of animals used, and to utilize alternatives to in vivo techniques. Mice were killed, and then their pancreas, liver, and testis were quickly removed and immersed into homogenizing buffer $(10 \mathrm{mM}$ Tris- $\mathrm{HCl}, \mathrm{pH} 7.5$, containing $1 \mathrm{mM}$ EDTA, $150 \mathrm{mM} \mathrm{NaCl}, 5 \mu \mathrm{g} / \mathrm{ml}$ leupeptin, 5 $\mu \mathrm{g} / \mathrm{ml}$ aprotinin, $1 \mu \mathrm{g} / \mathrm{ml}$ pepstatin $\mathrm{A}$, and $200 \mathrm{mM}$ phenylmethanesulfonyl fluoride). The tissues were then homogenized by using a Physcotron NS-50 homogenizer. One-fourth volume of $4 \times$ SDS sample buffer $(1 \times$ SDS sample buffer = $62.5 \mathrm{mM}$ Tris- $\mathrm{HCl}, \mathrm{pH}$ 6.8, containing 2\% SDS, 5\% 2mercaptoethanol, $10 \%$ glycerol, and $0.1 \%$ bromophenol blue) was added to each of the homogenates, which were then boiled for 5 minutes, and sonicated for 30 times. The resulting homogenates were subjected to immunoblot analysis.

\subsection{Immunoblot Analysis}

Immunoblot analysis was performed as described previously [16]. Briefly, proteins separated by SDS-PAGE on $7.5 \%$ of slab gels were transferred electrophoretically for 75 minutes at $100 \mathrm{~V}$ onto a polyvinylidene difluoride membrane (Millipore) in Transfer buffer (25 mM Tris, $192 \mathrm{mM}$ glycine, $10 \%$ methanol). The membrane was then incubated overnight at $4^{\circ} \mathrm{C}$ in Tris-buffered saline (TBS; $20 \mathrm{mM}$ Tris- $\mathrm{HCl}$, $\mathrm{pH} 7.5$, containing $150 \mathrm{mM} \mathrm{NaCl}$ ) supplemented with $10 \%$ non-fat milk. The membrane was next incubated with antiGOLSYN antibody $(1: 100)$, or anti- $\beta$-actin antibody (1:2000) for 2 hours at room temperature. It was thereafter washed 3 times with TBS containing $0.02 \%$ Tween 20 and then incubated with HRP-conjugated anti-rabbit IgG antibody (1:1000) or anti-mouse IgG antibody (1:5000) for 1 hour at room temperature. Finally, the proteins were visualized by use of an ECL PLUS Western Blotting Detection System (Amersham Biosciences Corp.).

\subsection{Immunohistochemistry}

Sections of mouse organs were prepared as described earlier [16]. Briefly, animals were perfused via the left ventricle of the heart with saline, under anesthesia by an intraperitoneal injection of pentobarbital $(250 \mathrm{mg} / \mathrm{kg}$, i.p.), and then perfused with $4 \%$ paraformaldehyde (PFA; Nacalai Tesque). After perfusion, the organs were removed, postfixed in $4 \%$ PFA for 24 hours at $4^{\circ} \mathrm{C}$, and then paraffin-embedded. Organ sections at $5 \mu \mathrm{m}$ in thickness were cut and deparaffinized in xylene. Next the sections were immersed in $0.3 \%$ hydrogen peroxide in methanol for 5 minutes to block endogenous peroxidase activity. Then they were incubated with $1 \%$ normal goat serum (Vector) at room temperature for 1 hour for blocking, followed by incubation with anti-GOLSYN antibody $(1: 100)$ at $4^{\circ} \mathrm{C}$ overnight in the presence or absence of an excess amount of the peptide used for the preparation of the antibody. After incubation with biotinylated anti-rabbit antibody against immunoglobulin $\mathrm{G}$ (1:200) for 30 minutes at room temperature, the antibody was detected with the avidin-biotin-peroxidase complex. Development was performed by incubation with diaminobenzidine (Nichirei Bioscience) for the times required to obtain brown-stained products. All sections were then counterstained with hematoxylin.

\subsection{Statistical Analysis}

Data were expressed as the means \pm S.E., which were obtained from 3 to 5 different experiments with 3 to 5 animals per group in each experiment. Statistical differences were evaluated by using Student's $t$-test. A p-value of less than 0.05 was considered to be statistically significant.

\section{RESULTS}

To determine the expression of Golsyn/Syntabulin protein in mouse peripheral organs, we prepared sections of various organs from adult ddY mice and immunostained them with anti-GOLSYN antibody. The sections were then processed with hematoxylin-staining for the identification of Golsyn/Syntabulin-positive cells. The specificity of the signals obtained with the antibody was verified by the absence of a positive immunoreaction following the addition of an excess amount of the peptide used for the preparation of the anti-GOLSYN antibody. 


\subsection{Distribution of Golsyn/Syntabulin in Mouse Periph- eral Organs}

\subsubsection{Gastrointestinal Tract}

Immunostaining of sections throughout stomach including the cardia and pylorus was performed. Strong signals for Golsyn/Syntabulin were observed in the fundic glands (Fig. 1A) and in the simple columnar epithelium of the gastric pits (Fig. 1A and C); whereas the signals were not detected in the presence of an excess amount of the peptide used for the generation of the antibody (Fig. 1B). A magnified section of fundic glands revealed an intense staining of the chief cells, but not of the parietal cells (Fig. 1D). The signal observed in these chief cells appeared to be stronger than that seen in the epithelial cells of the gastric pits (Fig. 1D versus A, C). In contrast to these cells, the $\mathrm{G}$ cells, which are endocrine cells located at the pyloric glands, were weakly reactive with the antibody (data not shown). There was no significant difference in the expression pattern of Golsyn/Syntabulin in the various regions of the stomach (data not shown).

Fig. (2) shows the distribution of Golsyn/Syntabulin in the small intestine. Strong signals for Golsyn/Syntabulin were observed in the intestinal villi and crypts (Fig. 2A). An adjacent section of small intestine used as a specificity control (immunogen-absorbed antibody) is shown in Fig. (2B). Microscopic examination of the intestinal villi at high mag- nification demonstrated that Golsyn/Syntabulin was predominantly expressed in the absorptive epithelial cells and plasmocytes, but not in the goblet cells (Fig. 2C). In the intestinal crypts, significant signal intensity was observed in the crypt cells of the epithelium, but not in Paneth cells (Fig. 2E). Positive signals were also found in Meissner's submucosal plexus and Auerbach's myenteric plexus, both of which are distributed all over the small intestines (Fig. 2D and $\mathbf{E}$ ). The small intestine is anatomically composed of 3 different regions, the so-called duodenum, jejunum, and ileum; but there was no significant difference in the expression pattern of Golsyn/Syntabulin among these 3 regions (data not shown).

\subsubsection{Lungs}

Prominent signals for Golsyn/Syntabulin were observed in the bronchioles and the alveolar ducts (Fig. 3A). Incubation of an adjacent serial section of lung tissue with the preabsorbed antibody failed to produce any staining (Fig. 3B). Golsyn/Syntabulin was specifically expressed in the bronchiolar epithelial cells (Fig. 3C). In the alveolar ducts, strong signals were detected in the alveolar type I cells; whereas no signal was found in the alveolar type II cells (Fig. 3D). No significant signals were detectable in the other regions of the lung.
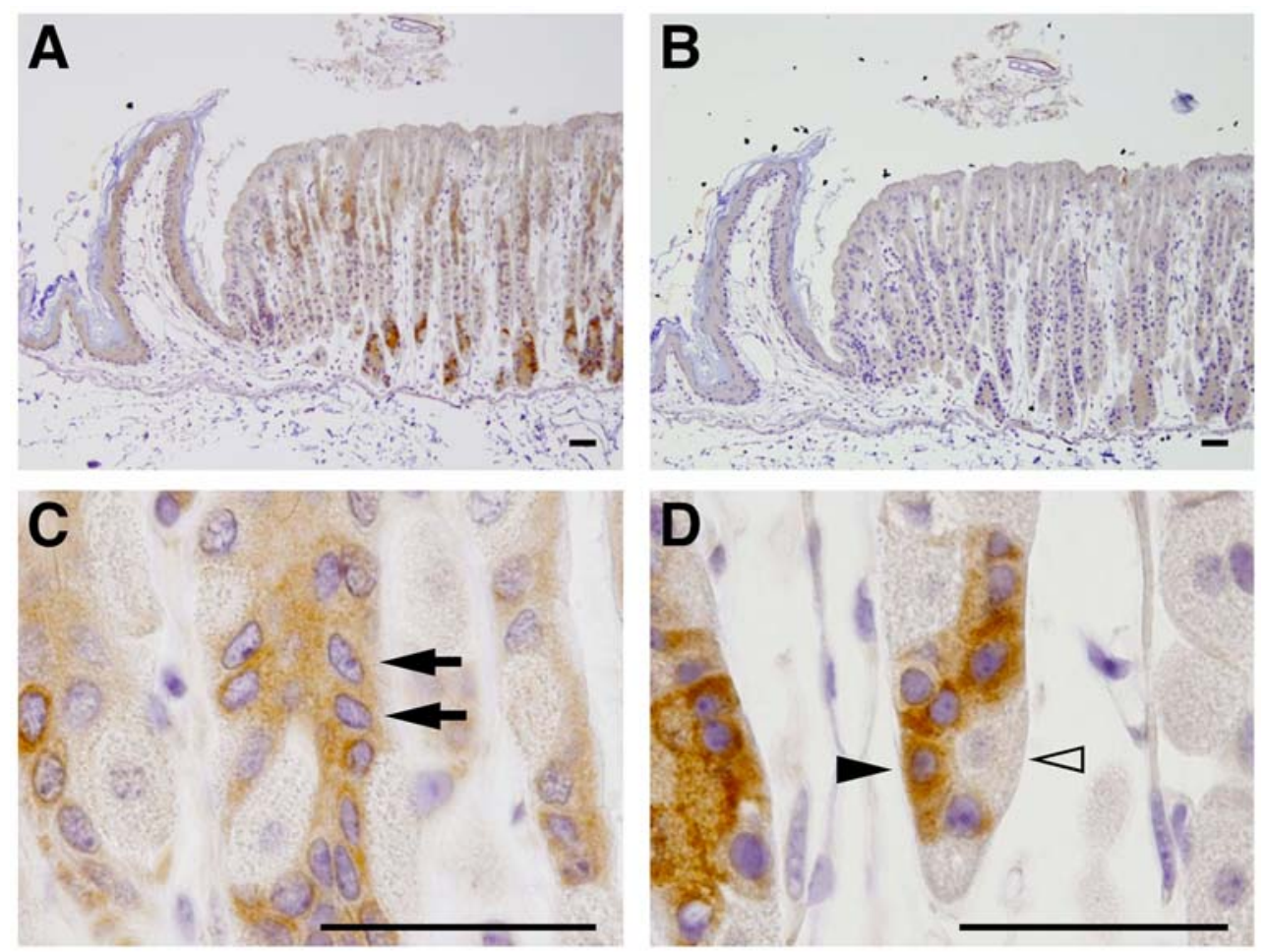

Fig. (1). Mouse stomach sections immunohistochemically stained with anti-GOLSYN antibody.

Stomach was collected from ddY mice ( 5 weeks of age), and serial sections were prepared at thickness of $5 \mu \mathrm{m}$ by use of a cryostat at $-20^{\circ} \mathrm{C}$. The sections were stained with anti-GOLSYN antibody, as described under "Materials and Methodology." DAB solution was used as the detection agent for Golsyn/Syntabulin immunoreactivity. All sections were counterstained with hematoxylin. (A) Gastric pits and fundic glands showing immunoreactivity to the anti-GOLSYN antibody. (B) Control experiment using anti-GOLSYN antibody preabsorbed with the peptide used for the generation of the antibody. Note that the control section in subsequent figures refers to the same type of control. (C) Epithelial cells of gastric pits (solid arrows). (D) Chief cells (solid arrowhead) and parietal cells (open arrowhead). Scale bars, $40 \mu \mathrm{m}$. Counterstaining of sections with hematoxylin-eosin or periodic acid-Schiff indicated the expression of Golsyn/Syntabulin in epithelial cells of gastric pits and chief cells. 

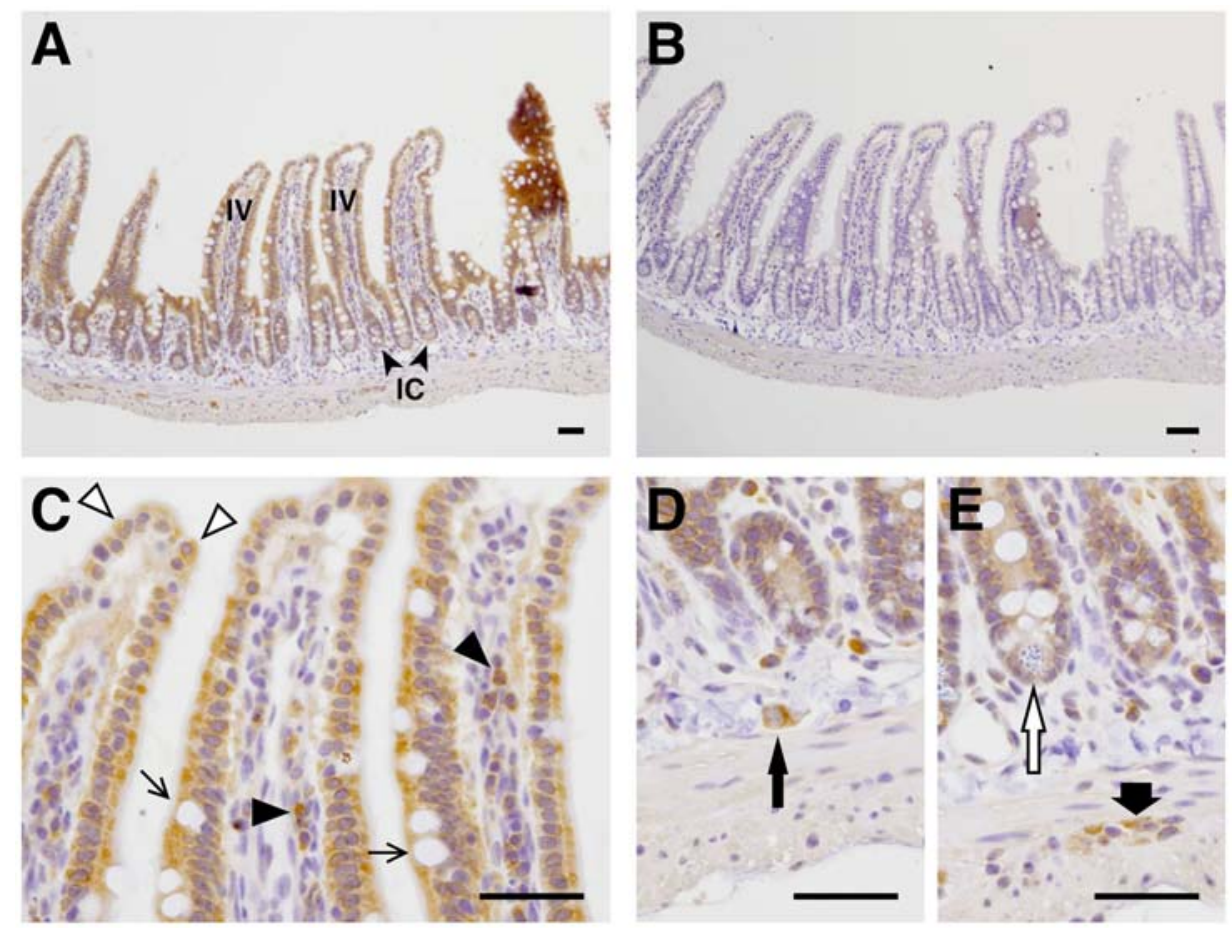

Fig. (2). Immunohistochemical detection of Golsyn/Syntabulin in the mouse small intestines.

Sections were prepared from the small intestines of ddY mice and stained with anti-GOLSYN antibody and hematoxylin as described in the legend of Fig. (1). (A) Intestinal villus (IV) and intestinal crypts (IC). (B) Control section from the same region. (C) Absorptive epithelial cells (open arrowheads), plasmacytes (solid arrowheads), and goblet cells (arrows). (D) Meissner's submucosal plexus (solid arrow). (E) Auerbach's myenteric plexus (solid arrow) and Paneth cells (open arrow). Scale bars, $40 \mu \mathrm{m}$.
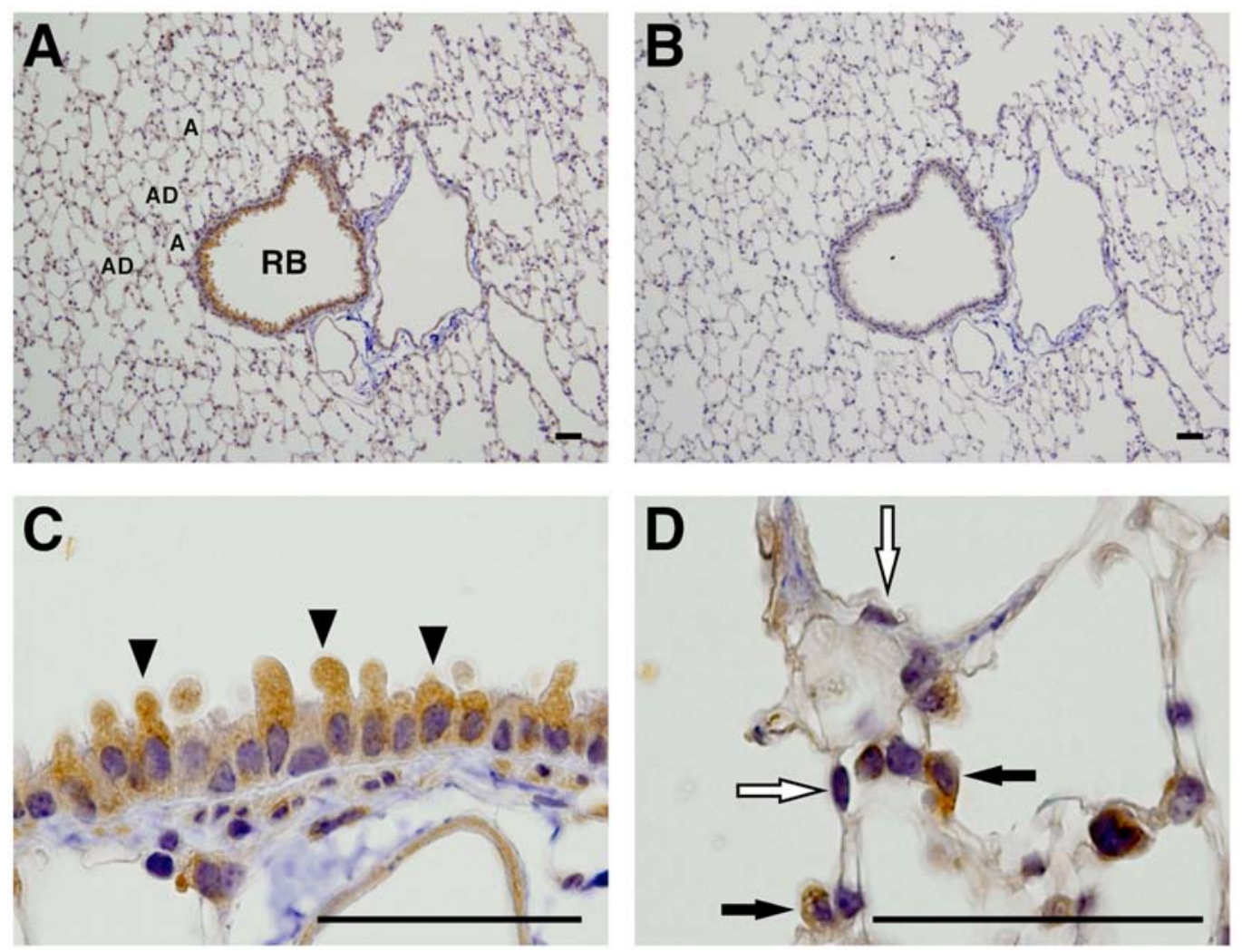

Fig. (3). Immunohistochemically stained sections of mouse lung.

Sections of lung were stained with anti-GOLSYN antibody and counterstained with hematoxylin. (A) Respiratory bronchiole (RB), alveolar ducts (AD), and alveoli (A). (B) Control section (C) Bronchiolar epithelial cells (solid arrowheads) of the bronchiole. (D) Alveolar type I cells (solid arrows) and alveolar type II cells (open arrows) of the alveolar ducts. Scale bars, $40 \mu \mathrm{m}$. 

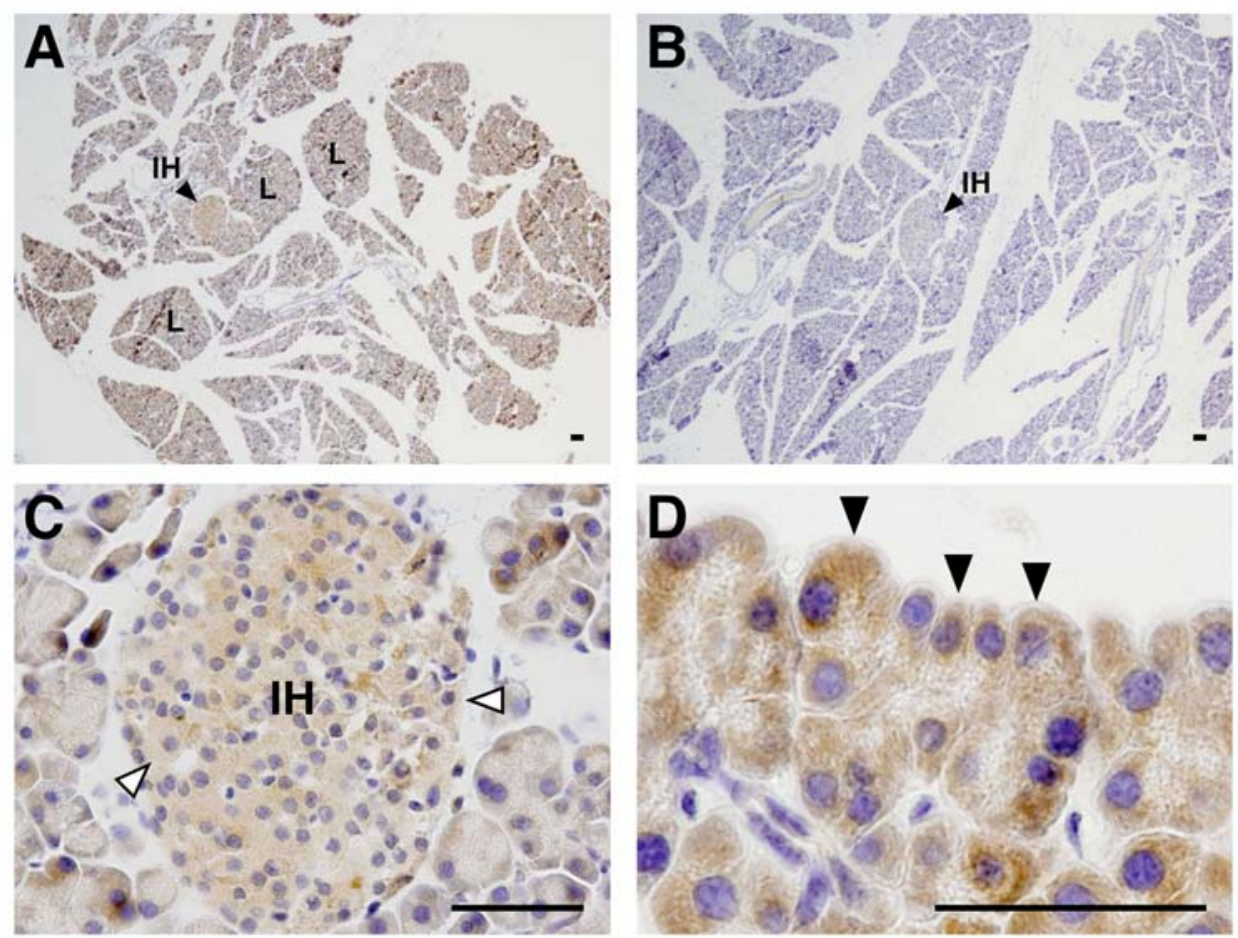

Fig. (4). Immunoreactivity of mouse pancreas with anti-GOLSYN antibody.

Sections of pancreas prepared from ddY mice were stained with anti-GOLSYN antibody and hematoxylin, as described in the legend of Fig. (1). (A) Islet of Langerhans (IH) and lobule (L) in pancreatic lobes. (B) Control section. (C) Pancreatic islet cells (open arrowheads). (D) Pancreatic acinar cells (solid arrowheads). Scale bars, $40 \mu \mathrm{m}$.

\subsubsection{Pancreas}

Strong signals for Golsyn/Syntabulin were detected throughout the pancreatic lobules (Fig. 4A). A control section of pancreas incubated with the preabsorbed antibody gave no immunoreaction (Fig. 4B). Higher magnification revealed intense signals in the pancreatic islet cells (Fig. 4C) and the pancreatic acinar cells (Fig. 4D). No significant signal was observed in the other regions of the pancreas.

\subsubsection{Male Reproductive Tract}

In the testis, strong signals for Golsyn/Syntabulin were observed in the seminiferous tubules, but not in the stroma (Fig. 5A). An immunoabsorbed control is shown in Fig. (5B). Higher magnification of the seminiferous tubules demonstrated an intense signal in the seminiferous epithelium (Fig. 5C, D, and E). In the seminiferous epithelium, strong signals were located in the spermatocytes (Fig. 5C) and spermatids (Fig. 5D), but no significant signals were found in the Sertoli cells or spermatogonia (Fig. 5E). Weak signals were observed in the spermatozoa (Fig. 5E), but they were also detected in those stained with anti-GOLSYN antibody in the presence of the antigen (data not shown).

In the epididymis, strong signals for Golsyn/Syntabulin were observed in the ductus epididymis (Fig. 6A). As shown in Fig. (6B), the signals were not observed in the sections of epididymis used as a specificity control. An intense signal was observed in the tall columnar cells, where it was mainly distributed in the peri-nuclear region (Fig. 6C and D). On the other hand, no signal was observed in the spermatozoa within the lumen of the ductus epididymis (Fig. 6C and D).
In the prostate, Golsyn/Syntabulin was abundantly expressed in the epithelium of prostate glands and deferent ducts (Fig. 7A, C, and D). The specificity control for the prostate is shown in Fig. (7B). Golsyn/Syntabulin was not distributed equally in the epithelial cells of the deferent ducts, as it was distributed on the basolateral side of the cytoplasm (Fig. 7D). Golsyn/Syntabulin was also detectable in the epithelial cells of the vesicular glands and coagulation glands (data not shown).

\subsection{Changes in Expression Level of Golsyn/Syntabulin in Pancreas by Fasting and Refeeding}

As was shown in Fig. (4), strong expression of Golsyn/Syntabulin was detected in the pancreatic acinar cells. These cells are known to contain many secretory vesicles, called zymogen granules, which contain digestive enzymes such as trypsin and amylase, and they secrete these enzymes into the pancreatic ducts [19]. To investigate the role of Golsyn/Syntabulin in the pancreatic secretion process, we examined the expression of Golsyn/Syntabulin in the gland during fasting and refeeding, which actions affect the secretion of pancreatic juice via secretory vesicles. Immunoblotting with anti-GOLSYN antibody revealed that a single band with a molecular mass of approximately $90 \mathrm{kDa}$ was detected when immunoblot analysis of the pancreas, liver, and testis was conducted (Fig. 8). In the pancreas and liver, fasting for 24 hours drastically decreased the expression levels of Golsyn/Syntabulin, which were decreased to $20 \%$ and $50 \%$, respectively, of the expression levels in the fed control mice. Refeeding for 24 hours after this fasting recovered its level to about $80 \%$ of the control level in both pancreas and liver (Fig. 8). On the other hand, neither fasting nor refeeding 

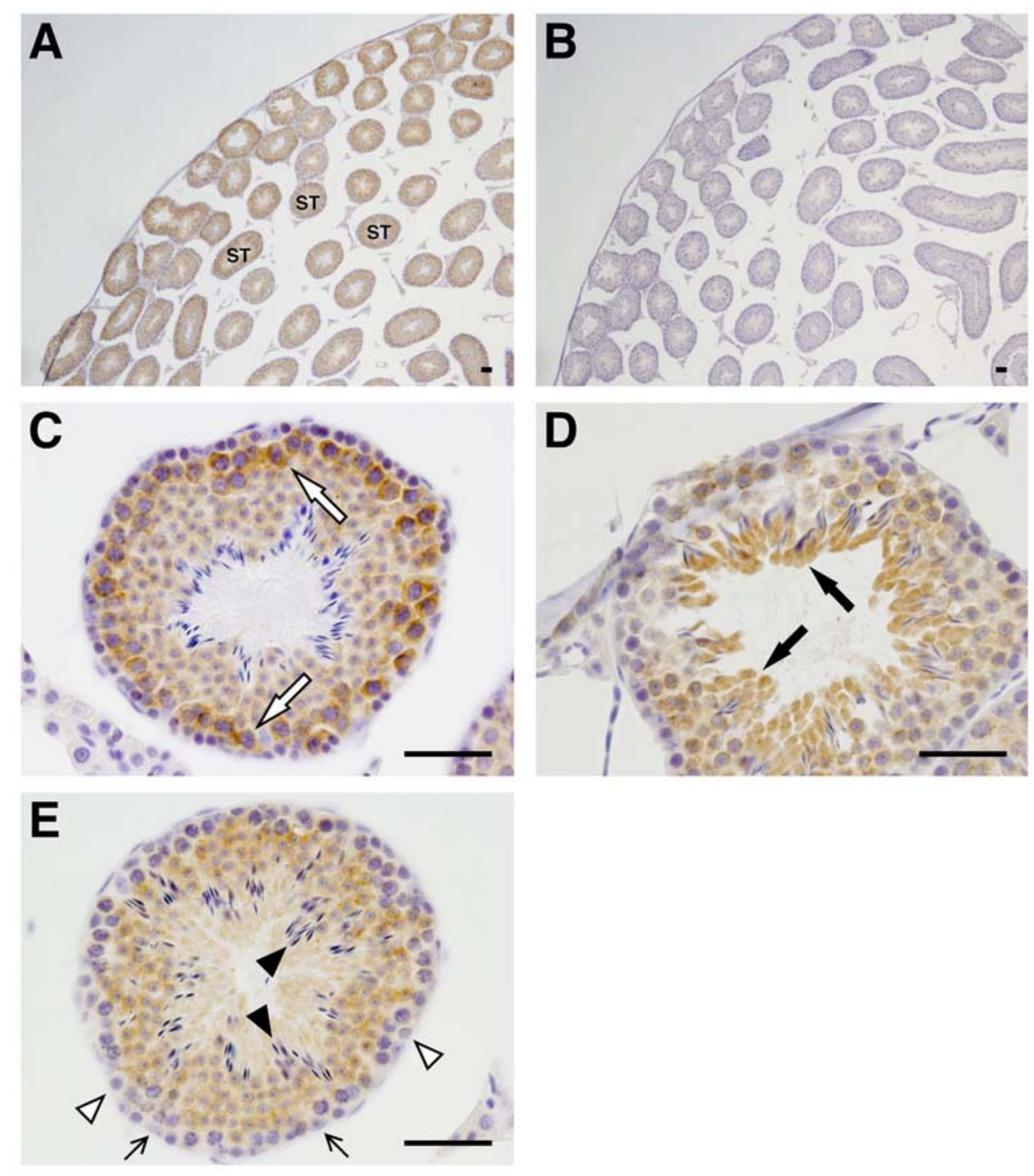

Fig. (5). Mouse testis sections reacted with anti-GOLSYN antibody.

Sections of testis were prepared from ddY mice and stained with anti-GOLSYN antibody, as described in the legend in Fig. (1). (A) Seminiferous tubule (ST) and stroma in testis. (B) Control section. (C) Spermatocytes (open arrows). (D) Spermatids (solid arrows). (E) Sertoli cells (arrows), spermatogonia (open arrowheads), and spermatozoa (solid arrowheads). Scale bars, $40 \mu \mathrm{m}$.

affected Golsyn/Syntabulin expression in the testis, a gland that has no secretory function for food digestion (Fig. 8).

\subsection{Effect of Gastrin on Expression of Golsyn/Syntabulin}

Gastrin is one of the most important bioactive substances in the gastrointestinal tract; and it is released from G cells, which are mainly located in the pyloric glands of the stomach [20,21]. Vagal nerve stimulation caused by feeding stimulates acid secretion from parietal cells of the stomach through binding of gastrin to the receptors for cholecystokinin (CCK)-B [22, 23]. Gastrin also plays an important role in pancreatic acinar cells: its binding to the CCK-B receptor induces exocytosis of zymogen granules in acinar cells [24]. To know the relationship between the secretory process in acinar cells and Golsyn/Syntabulin expression, we studied the effect of gastrin on Golsyn/Syntabulin expression in the pancreas of fasted mice. Mice were injected with saline or 1 $\mathrm{mg} / \mathrm{kg}$ gastrin at 24 hours after fasting, and tissue homogenates from the mice were then prepared and subjected to im- munoblot analysis using the anti-GOLSYN antibody. In the pancreas, the level of Golsyn/Syntabulin was markedly increased ( 2.5 -fold increase) by the gastrin injection, whereas it was not affected by saline administration (Fig. 9). In liver and testis, neither gastrin nor saline affected Golsyn/Syntabulin expression (Fig. 9). These results suggest a close relationship between secretion of digestive enzymes and Golsyn/Syntabulin expression in pancreatic acinar cells.

\subsection{Effect of Pilocarpine, a Vagal Nerve Stimulant, on Expression of Golsyn/Syntabulin}

As mentioned above, vagal nerve stimulation caused by feeding plays an important role in promoting digestion of foods in the gastrointestinal tract [25]. So, we then examined the effect of a vagal nerve stimulant, pilocarpine, on Golsyn/Syntabulin expression in the mouse pancreas. Mice were housed with free access to food and water and then intraperitoneally injected with pilocarpine, after which homogenates were prepared from the pancreas and subjected to immuno- 

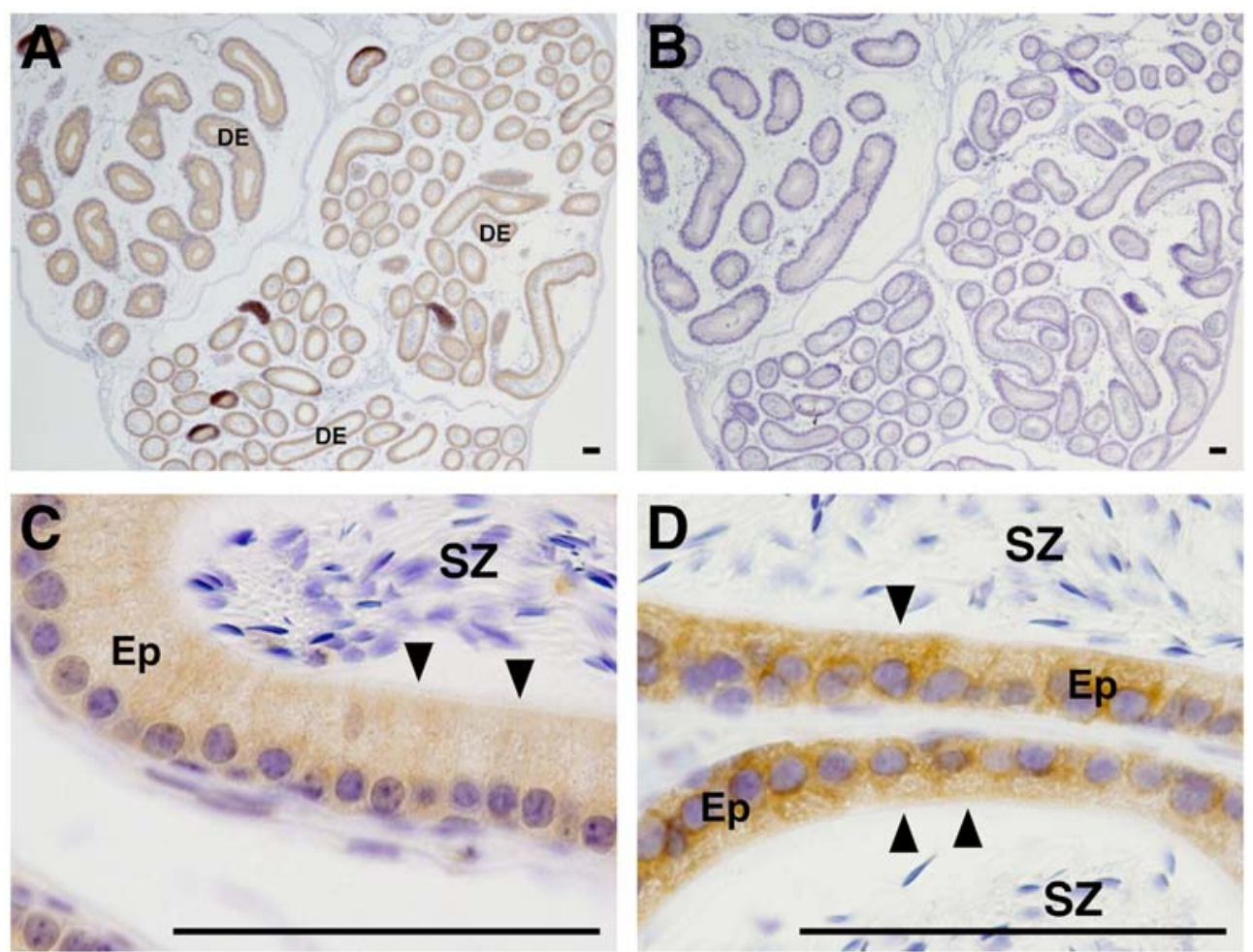

Fig. (6). Immuno-detection of Golsyn/Syntabulin in the mouse epididymis.

Sections of epididymis were prepared from ddY mice and stained with anti-GOLSYN antibody, as described in the legend in Fig. (1). (A) Ductus epididymis (DE). (B) Control section. (C) and (D) Tall columnar cells (solid arrowheads) and spermatozoa (SZ) within the lumen of the ductus epididymis. Ep, epithelium. Scale bars, $40 \mu \mathrm{m}$.
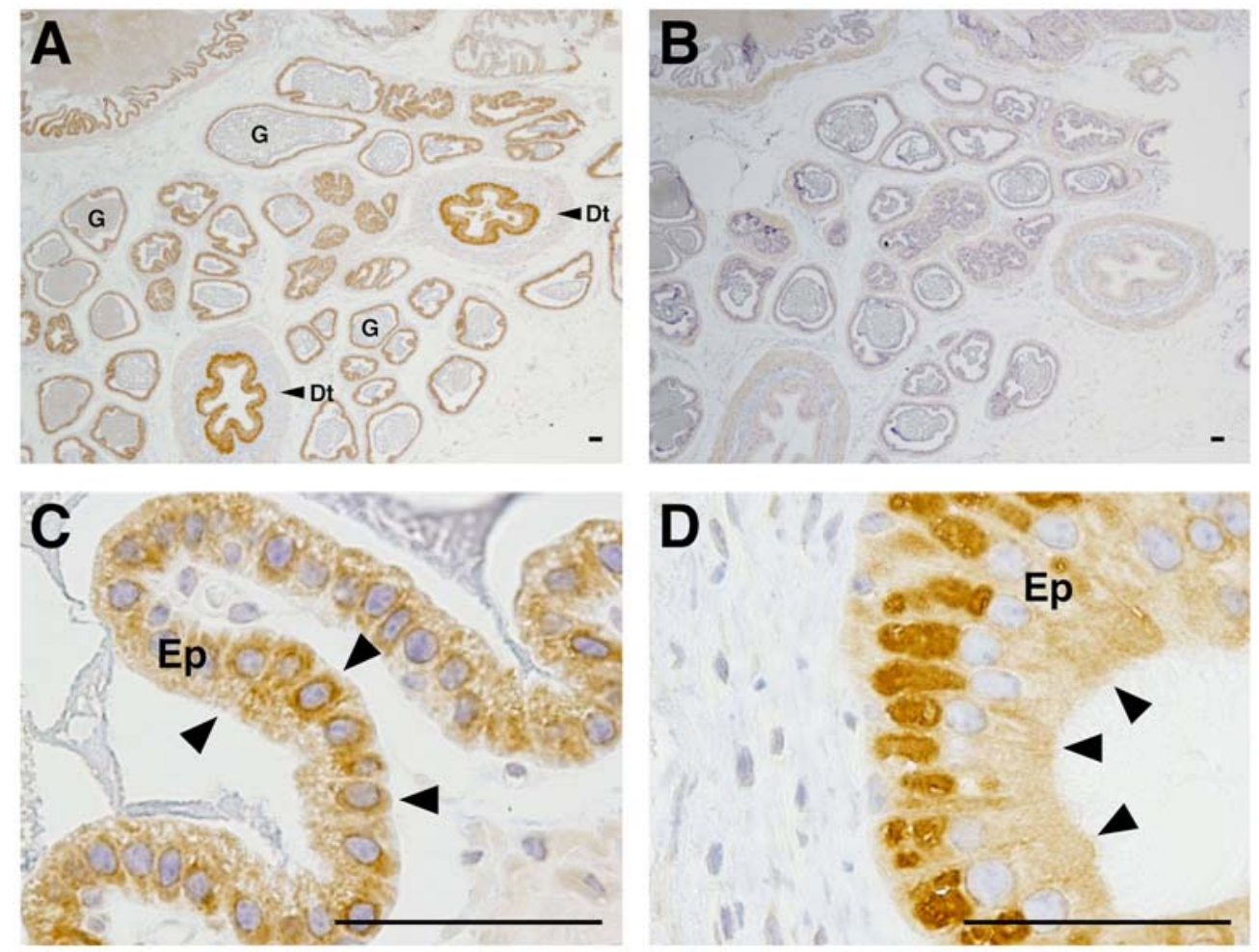

Fig. (7). Mouse prostate sections reacted with anti-GOLSYN antibody.

Sections of prostate were stained with anti-GOLSYN antibody and counterstained with hematoxylin as described in the legend of Fig. (1). (A) Deferent duct (Dt) and gland (G). (B) Control section. (C) Epithelial cells (EP, solid arrowheads) of a prostate gland. (D) Epithelial cells of a deferent duct (solid arrowheads). Scale bars, $40 \mu \mathrm{m}$. 

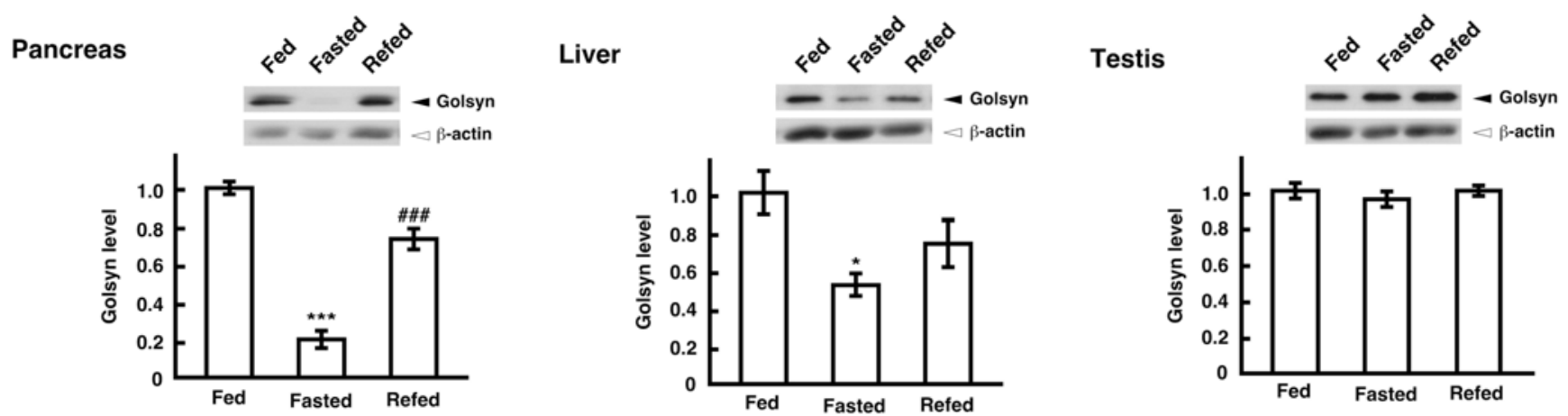

Fig. (8). Effect of fasting and refeeding on Golsyn/Syntabulin expression in pancreas.

Homogenates were prepared from pancreas, liver, and testis of ddY mice that had been fed, fasted, or refed, as described in "Materials and Methodology;" and they were then subjected to immunoblot analysis using anti-GOLSYN antibody. The results of densitometric analysis of the data shown in the upper panels are indicated in the lower panels, in which each column represents the mean \pm S.E $(n=5)$. Golsyn/Syntabulin level is indicated as the fold increase over the expression level in fed mice. *, ***: $\mathrm{P}<0.05$, $\mathrm{P}<0.001$, respectively, compared with value for the fed group. ${ }^{\# \# \#}$ : $\mathrm{P}<0.001$, compared with value for the fasted group.
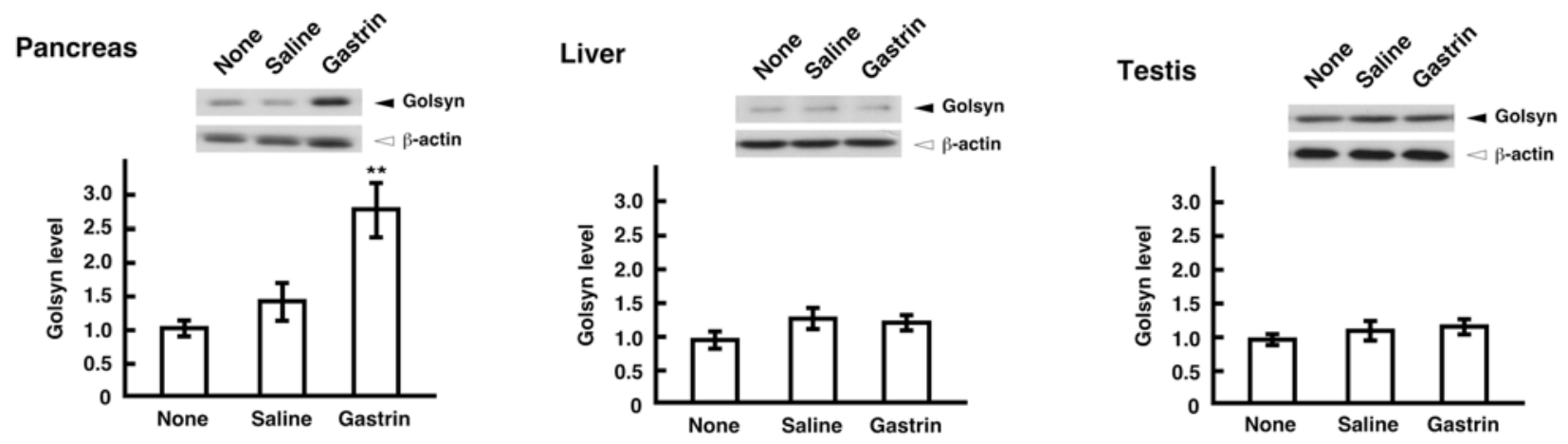

Fig. (9). Effect of gastrin administration on Golsyn/Syntabulin expression in pancreas.

ddY mice fasted for 24 hours were injected with saline or $1 \mathrm{mg} / \mathrm{kg}$ gastrin. At $30 \mathrm{~min}$ after the injection, homogenates were prepared from pancreas, liver, and testis. The upper panels show an immunoblot analysis of the homogenates using anti-GOLSYN antibody. Quantitative analysis of Golsyn/Syntabulin protein was done on the immunoblots, and the data obtained from this analysis are indicated in the lower panels. Golsyn/Syntabulin levels are indicated as the fold increase over the expression level in the untreated fasted groups. Each bar represents the mean \pm S.E. of 5 experiments. **: $\mathrm{P}<0.01$, compared with the value for the saline-injected group.

blotting. As shown in Fig. (10), Golsyn/Syntabulin expression in the pancreas was elevated up to 2.5 -fold at $15-30$ minutes after the pilocarpine injection; and the elevated expression rapidly decreased thereafter. At 2 hours after pilocarpine addition, its expression level was approximately $10 \%$ of that in the untreated (control) mice and thereafter gradually recovered to the control level.

\subsection{Zymogen Granules in Pancreatic Acinar Cells of the Fasted Mice}

Zymogen granules in pancreatic acinar cells contain various enzymes such as trypsin, amylase, and lipase for food digestion [26]. The size of zymogen granules is known to enlarge in response to food deprivation $[27,28]$. We prepared pancreatic sections from fed, fasted, and refed mice and stained the sections with hematoxylin-eosin. As shown in Fig. (11B), the area occupied by zymogen granules in the acinar cells increased at 24 hours after food deprivation: Acinar cells became rich in zymogen granules in these fasted mice. Refeeding after this food deprivation (Fig. 11C) decreased the area occupied by granules to the control level (Fig. 11A). On the other hand, alteration in the number of pancreatic acinar cells in the fasted and refed mice compared with the number for the fed ones was not observed (data not shown).

\subsection{Zymogen Granules in Pancreatic Acinar Cells of Pilocarpine-Treated Mice}

We next observed pancreatic acinar cells of the mice injected with pilocarpine. As shown in Fig. (12), pilocarpine markedly decreased the area occupied by zymogen granules at early times (e.g., $30 \mathrm{~min}, 1$ hour, and 2 hours) after its administration. Thereafter, the area of zymogen granules in the acinar cells was recovered to the level seen in the control mice (compare Cont. and $24 \mathrm{~h}$ in Fig. 12).

\section{DISCUSSION}

Earlier, we demonstrated that Golsyn/Syntabulin is ubiquitously expressed in various mouse organs including the brain at mRNA and protein levels $[16,17]$. In the brain, nerve cells, but not glial cells, express Golsyn/Syntabulin; however, the cell types expressing Golsyn/Syntabulin in the organs other than the brain remained unclear. In this present study, we determined the expression of Golsyn/Syntabulin in 


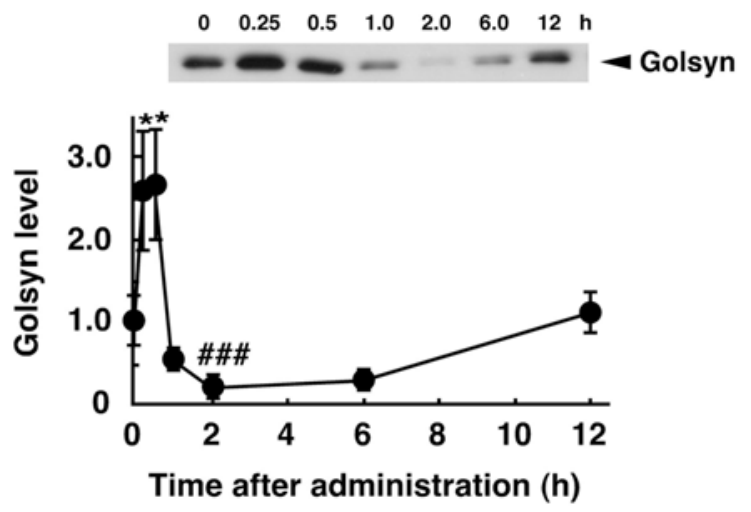

Fig. (10). Time course of Golsyn/Syntabulin expression in pancreas after pilocarpine administration.

Pancreatic homogenates were prepared from ddY mice at the indicated times after pilocarpine injection and then subjected to immunoblot analysis using anti-GOLSYN antibody. The arrowhead in the upper panel indicates the position of Golsyn/Syntabulin. Each point in the lower panel represents the mean \pm S.E. of 3 experiments, $\mathrm{n}=3$. *: $\mathrm{P}<0.05$, vs. the fed group. ${ }^{\# \#}$ : $\mathrm{P}<0.001$, vs. the group at $15 \mathrm{~min}$ after pilocarpine administration. The Golsyn/Syntabulin level is indicated as the fold increase over the level for the untreated fasted group.

various mouse peripheral organs by immunohistochemical analysis using anti-GOLSYN antibody and found that Golsyn/Syntabulin was abundantly expressed in the glandular epithelium of various peripheral organs: In exocrine glands, specific expression of Golsyn/Syntabulin was observed in cell types that are known to be secretory cells, such as chief cells in the stomach, alveolar type II cells and bronchiolar epithelial cells in lung, pancreatic acinar cells, and glandular epithelial cells in the male reproductive tract; and in endocrine glands, Golsyn/Syntabulin was detected in pancreatic islet cells, which are endocrine cells that produce and release hormones including insulin and glucagon [29]. Thus, Golsyn/Syntabulin was expressed not only in exocrine cells but also in endocrine cells in the periphery, suggesting that this protein plays an important role in secretory processes.

Besides that in glandular epithelium, Golsyn/Syntabulin was detectable in neuronal cells of peripheral plexuses such as Meissner's submucosal plexus and Auerbach's myenteric plexus in the small intestines (see Fig. 2D and E). Golsyn/Syntabulin has been reported to be ubiquitously expressed in nerve cells of various brain regions of postnatal and adult mice $[16,17]$. It thus appears that this protein plays a significant role in nerve cells of the periphery in addition to those of the brain.

In the last half of this study, we focused on pancreatic acinar cells to examine the role of Golsyn/Syntabulin in the secretory process, because acinar cells are frequently used to investigate the mechanism of transport and exocytotic processes of secretory vesicles [30, 31]. Food deprivation for 24 hours decreased markedly the expression of Golsyn/Syntabulin in pancreas and liver, but it did not affect that in the testis, which has no secretory glands for the digestion of food (see Fig. 8). The expression level of Golsyn/Syntabulin was recovered to almost the control level by refeeding, suggesting that its expression is closely associated with food intake. Gastrin, a hormone that stimulates zy-
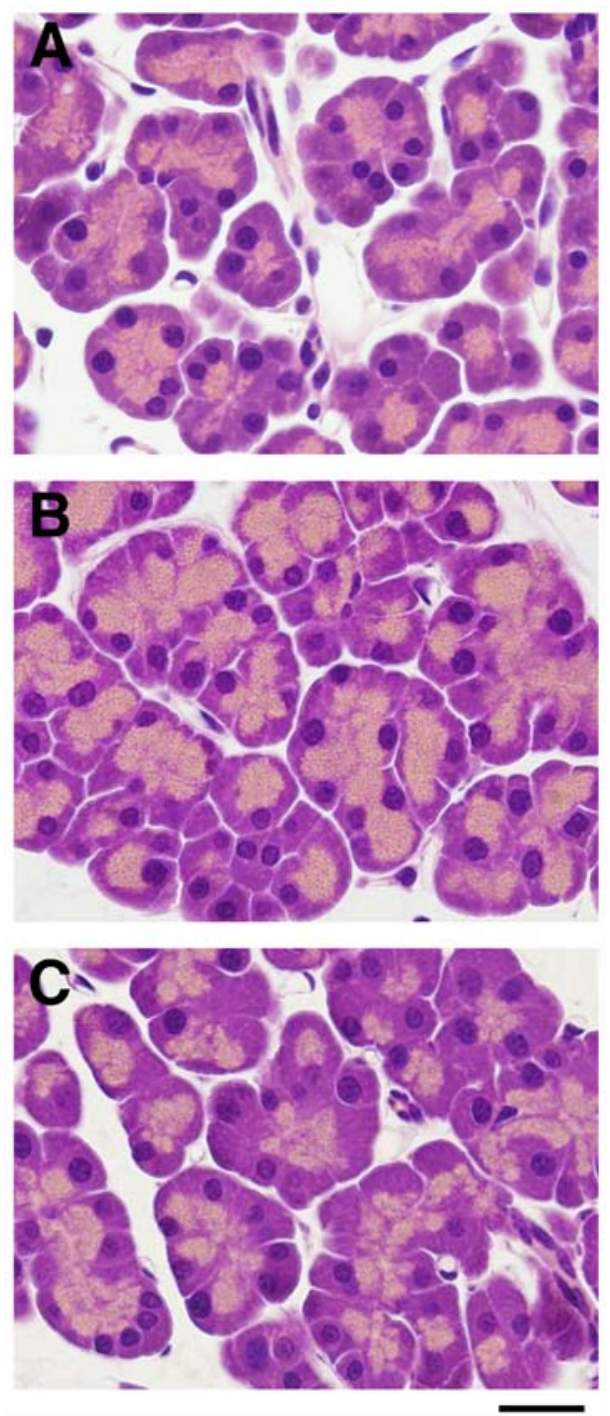

Fig. (11). Zymogen granules in pancreatic acinar cells of fasted mice.

Sections of pancreas were prepared from the fed (A), fasted (B), and refed $(\mathbf{C})$ mice and then stained with hematoxylin-eosin. Note that zymogen granules are stained light red with hematoxylineosin, owing to their reactivity with eosin. Scale bar, $20 \mu \mathrm{m}$.

mogen granule exocytosis in acinar cells, led to remarkable increase in Golsyn/Syntabulin expression in mice injected with this hormone. Furthermore, pilocarpine, a stimulator of the vagus nerve, elevated Golsyn/Syntabulin expression significantly (Fig. 10) and concomitantly reduced the area occupied by zymogen granules in the pancreatic acinar cells (Fig. 12). This reduction could have resulted from the exocytosis of zymogen granules, because digestive zymogen granules are utilized for the release of enzymes in response to vagal stimulation $[32,33]$. In terms of area, zymogen granules in the acinar cells were recovered to the control level after pilocarpine administration (see Fig. 12), but the Golsyn/Syntabulin level was still approximately $40 \%$ of the level seen in the untreated mice (see Fig. 10, $6 \mathrm{~h}$ ). These results are summarized in Fig. (13), which shows the effect of food deprivation, gastrin, and pilocarpine on Golsyn/Syntabulin level and the area occupied by zymogen granules. The Golsyn/Syntabulin level appears to correlate 

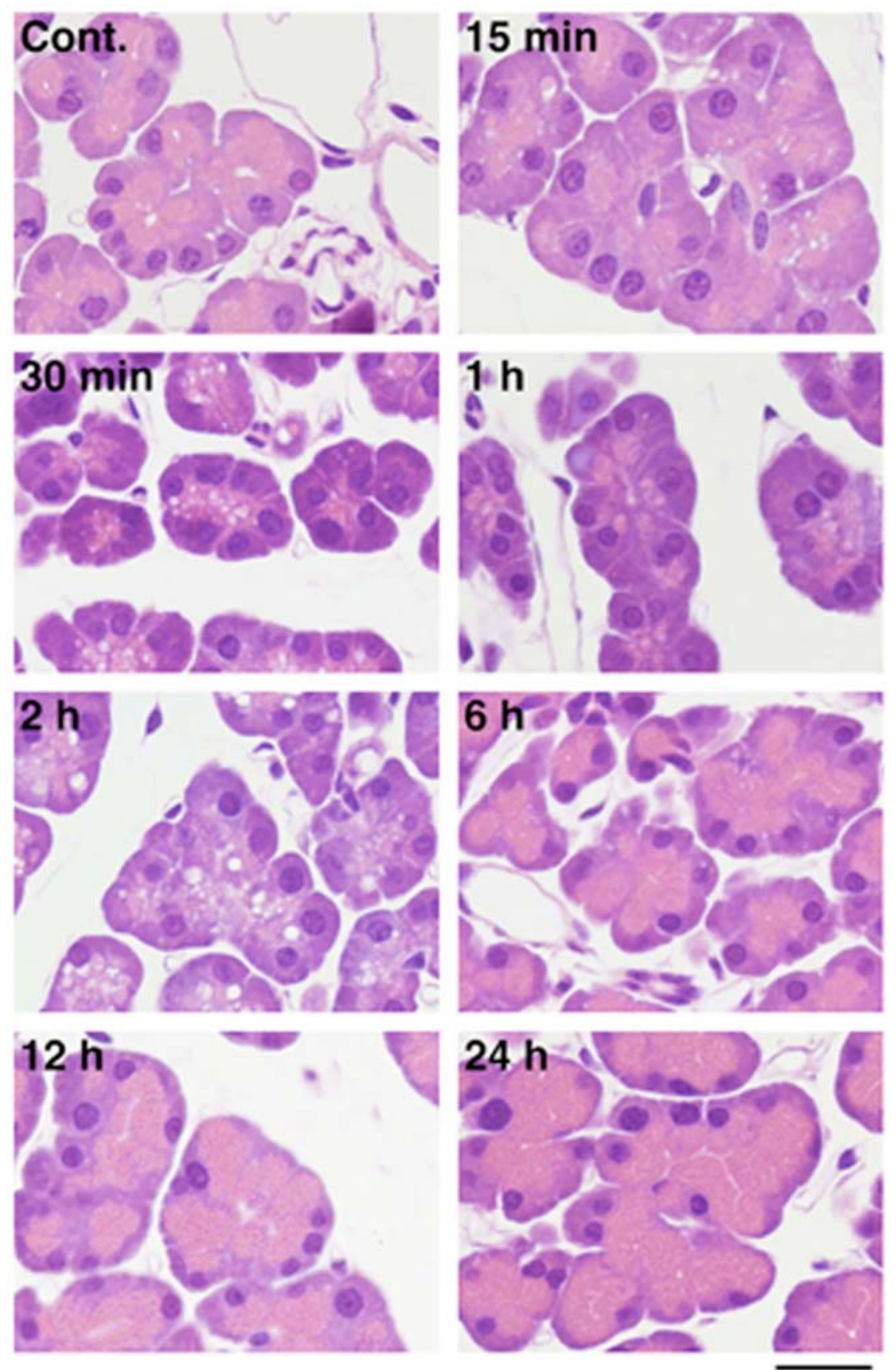

Fig. (12). Zymogen granules in pancreatic acinar cells after administration of pilocarpine.

Sections of pancreas were prepared from the mice at the indicated times after injection of pilocarpine. The sections of the pancreas were stained with hematoxylin-eosin. Scale bar, $20 \mu \mathrm{m}$.

with the process of secretion, but not with the area occupied by zymogen granules. Therefore, Golsyn/Syntabulin may play an important role in the processes of transport and/or exocytosis, rather than in the formation and/or maturation of zymogen granules in pancreatic acinar cells.

In neurons, GOLSYN/Syntabulin acts as a linker that attaches syntaxin-1 cargo vesicles to kinesin I, enabling the transport of the vesicles to neuronal processes [13]. This fact supports our indication that Golsyn/Syntabulin is involved in secretory vesicle transport in epithelial cells in the periphery. However, it is unlikely that Golsyn/Syntabulin exerts its action through association with syntaxin 1 , because syntaxin 1 is specifically expressed in neuronal cells of central and peripheral nerves [34]. A homology search for syntaxin 1 picked up syntaxins 2,3 , and 4 , which, like syntaxin 1 , belong to the SNARE family of proteins that mediates membrane fusion of organelles and/or transport vesicles [35]. Since syntaxins 2,3 , and 4 are expressed in the periphery as well as in the brain [34] and are localized to both plasma membrane and transport vesicles in epithelial cells [36, 37], they are potential candidates as binding partners for Golsyn/Syntabulin in epithelial cells. In fact, we have found that syntaxins 3 and 4, but not syntaxin 2, formed a complex with Golsyn/Syntabulin in HeLa cells that had been co- 


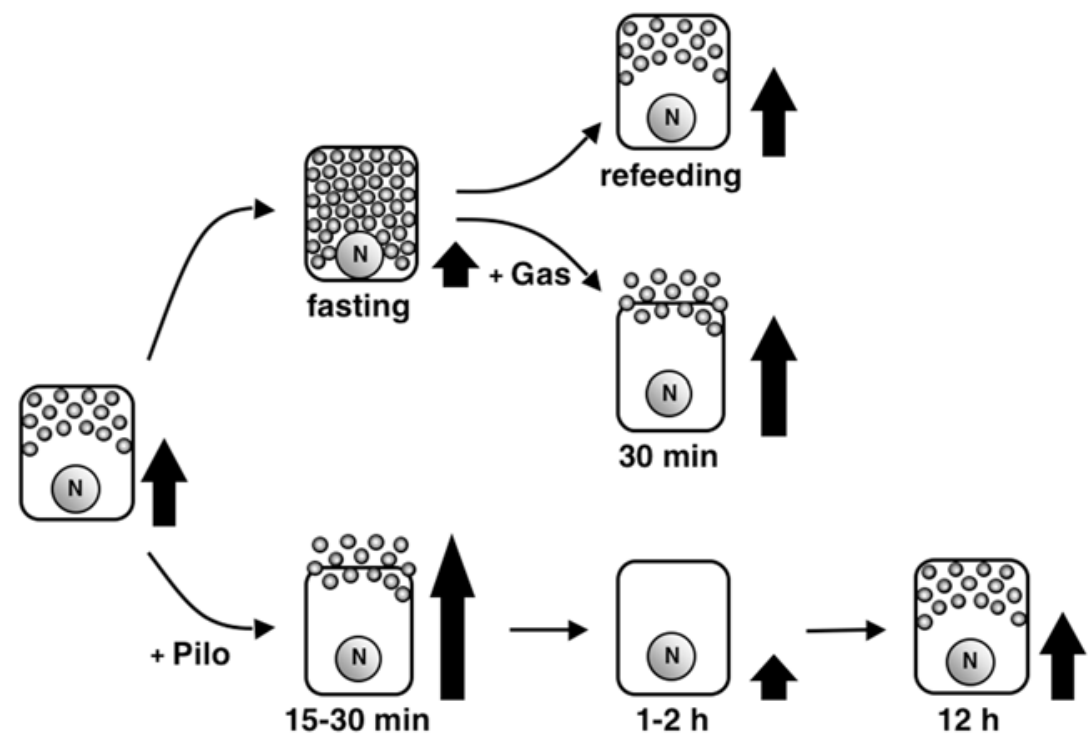

Fig. (13). Role of Golsyn/Syntabulin in the secretory process in pancreatic acinar cells.

The length of the closed arrows represents the expression level of Golsyn/Syntabulin. Gas, gastrin; Pilo, pilocarpine; N, nucleus.

transfected with cDNAs for syntaxins 3 or 4 and Golsyn/Syntabulin (unpublished data).

\section{CONCLUSIONS}

In conclusion, Golsyn/Syntabulin was abundantly expressed in secretory cells in glandular epithelium. Its expression level in the pancreas was drastically decreased by fasting. On the other hand, its expression was increased by gastrin and pilocarpine. These findings may indicate that Golsyn/Syntabulin plays an important role in secretory vesicle transport and/or exocytosis in secretory cells in the periphery. Further studies including the loss-of-function approach for studying Golsyn/Syntabulin in a variety of cells should provide us cues to clarify the physiological role of Golsyn/Syntabulin in vesicular trafficking.

\section{ACKNOWLEDGEMENTS}

We thank T. Miyake, Y. Mukuura, H. Iwasaki, and I. Ogita for technical assistance. This work was supported in part by a Fund for "Research for the Future" Program from the Japan Society for the Promotion of Science (JSPS) and Ministry of Education, Culture, Sports, Science and Technology (MEXT).

\section{ABBREVIATION}

GOLSYN = Golgi-localized syntaphilin-related protein

\section{REFERENCES}

[1] Rothman JE. Mechanisms of intracellular protein transport. Nature 1994; 372: 55-63.

[2] Bennett MK, Scheller RH. A molecular description of synaptic vesicle membrane trafficking. Annu Rev Biochem 1994; 63: 63100.

[3] Pfeffer SR. Transport-vesicle targeting: tethers before SNAREs. Nat Cell Biol 1999; 1: E17-22.

[4] Rothman JE, Wieland FT. Protein sorting by transport vesicles. Science 1996; 272: 227-34.

[5] Zerial M, Stenmark H. Rab GTPases in vesicular transport. Curr Opin Cell Biol 1993; 5: 613-20.

[6] Hirokawa N. Kinesin and dynein superfamily proteins and the mechanism of organelle transport. Science 1998; 279: 519-26.
[7] Hong W. SNAREs and traffic. Biochim Biophys Acta 2005; 1744: 493-517.

[8] Setou M, Seog DH, Tanaka Y, et al. Glutamate-receptor-interacting protein GRIP1 directly steers kinesin to dendrites. Nature 2002 ; 417: 83-7.

[9] Nakagawa T, Setou M, Seog D, et al. A novel motor, KIF13A, transports mannose-6-phosphate receptor to plasma membrane through direct interaction with AP-1 complex. Cell 2000; 103: 56981.

[10] Setou M, Nakagawa T, Seog DH, Hirokawa N. Kinesin superfamily motor protein KIF17 and mLin-10 in NMDA receptorcontaining vesicle transport. Science 2000; 288: 1796-802.

[11] Lao G, Scheuss V, Gerwin CM, et al. Syntaphilin: a syntaxin-1 clamp that controls SNARE assembly. Neuron 2000; 25: 191-201.

[12] Das S, Gerwin C, Sheng ZH. Syntaphilin binds to dynamin-1 and inhibits dynamin-dependent endocytosis. J Biol Chem 2003; 278: 41221-6.

[13] Su Q, Cai Q, Gerwin C, Smith CL, Sheng ZH. Syntabulin is a microtubule-associated protein implicated in syntaxin transport in neurons. Nat Cell Biol 2004; 6: 941-53.

[14] Cai Q, Pan PY, Sheng ZH. Syntabulin-kinesin-1 family member 5B-mediated axonal transport contributes to activity-dependent presynaptic assembly. J Neurosci 2007; 27: 7284-96.

[15] Cai Q, Gerwin C, Sheng ZH. Syntabulin-mediated anterograde transport of mitochondria along neuronal processes. J Cell Biol 2005; 170: 959-69.

[16] Funakoshi E, Hamano A, Fukui M, et al. Molecular cloning of the $\mathrm{m}$-Golsyn gene and its expression in the mouse brain. Gene Exp 2006; 13: 27-40.

[17] Funakoshi E, Fukui M, Hamano A, et al. Expression of mGolsyn/Syntabulin gene during mouse brain development. Neurosci Lett 2006; 403: 244-9.

[18] Funakoshi E, Nakagawa KY, Hamano A, et al. Molecular cloning and characterization of gene for Golgi-localized syntaphilin-related protein on human chromosome 8q23. Gene 2005; 344: 259-71.

[19] Palade G. Intracellular aspects of the process of protein synthesis Science 1975; 189: 347-58.

[20] Beltrami CA, Fabris G, Marzola A, et al. Staining of gastrin cells with lead-haematoxylin. Histochem J 1975; 7: 95-9.

[21] Boel E, Vuust J, Norris F, et al. Molecular cloning of human gastrin cDNA: evidence for evolution of gastrin by gene duplication. Proc Natl Acad Sci USA 1983; 80: 2866-9.

[22] Sandvik AK, Waldum HL. CCK-B (gastrin) receptor regulates gastric histamine release and acid secretion. Am J Physiol 1991; 260: G925-8. 
[23] Kanai S, Hosoya H, Akimoto S, et al. Gastric acid secretion in cholecystokinin-1 receptor, -2 receptor, and $-1,-2$ receptor gene knockout mice. J Physiol Sci 2009; 59: 23-9.

[24] Saillan-Barreau C, Clerc P, Adato M, et al. Transgenic CCK$\mathrm{B} /$ gastrin receptor mediates murine exocrine pancreatic secretion. Gastroenterology 1998; 115: 988-96.

[25] Rogers RC, McTigue DM, Hermann GE. Vagovagal reflex control of digestion: afferent modulation by neural and "endoneurocrine" factors. Am J Physiol 1995; 268: G1-10.

[26] Posthuma G, Slot JW, Geuze HJ. Immunocytochemical assays of amylase and chymotrypsinogen in rat pancreas secretory granules. Efficacy of using immunogold-labeled ultrathin cryosections to estimate relative protein concentrations. J Histochem Cytochem 1984; 32: 1028-34.

[27] Ermak TH, Rothman SS. Zymogen granules of pancreas decrease in size in response to feeding. Cell Tissue Res 1981; 214: 51-66.

[28] Aughsteen AA, Cope GH. Changes in the size and number of secretion granules in the rat exocrine pancreas induced by feeding or stimulation in vitro. A morphometric study. Cell Tissue Res 1987; 249: 427-36.

[29] Erlandsen SL. Types of pancreatic islet cells and their immunocytochemical identification. Monogr Pathol 1980; 21: 140-55.
[30] Saegusa C, Kanno E, Itohara S, Fukuda M. Expression of Rab27Bbinding protein Slp1 in pancreatic acinar cells and its involvement in amylase secretion. Arch Biochem Biophys 2008; 475: 87-92.

[31] Lee M, Chung S, Uhm DY, Park MK. Regulation of zymogen granule exocytosis by $\mathrm{Ca}^{2+}$, cAMP, and $\mathrm{PKC}$ in pancreatic acinar cells. Biochem Biophys Res Commun 2005; 334: 1241-7.

[32] Kaminski DL, Ruwart MJ, Willman VL. The effect of electrical vagal stimulation on canine pancreatic exocrine function. Surgery 1975; 77: 545-52.

[33] Eisenberg MM, Orahood RC. Vagal stimulation of the exocrine pancreas. Ann Surg 1971; 173: 462-6.

[34] Bennett MK, García-Arrarás JE, Elferink LA, et al. The syntaxin family of vesicular transport receptors. Cell 1993; 74: 863-73.

[35] Ungar D, Hughson FM. SNARE protein structure and function. Annu Rev Cell Dev Biol 2003; 19: 493-517.

[36] Fujita H, Tuma PL, Finnegan CM, Locco L, Hubbard AL. Endogenous syntaxins 2, 3 and 4 exhibit distinct but overlapping patterns of expression at the hepatocyte plasma membrane. Biochem $\mathrm{J}$ 1998; 329: 527-38.

[37] Band AM, Kuismanen E. Localization of plasma membrane tSNAREs syntaxin 2 and 3 in intracellular compartments. BMC Cell Biol 2005; 6: 26 .

(C) Oda et al.; Licensee Bentham Open.

This is an open access article licensed under the terms of the Creative Commons Attribution Non-Commercial License (http://creativecommons.org/licenses/by-nc/3.0/) which permits unrestricted, non-commercial use, distribution and reproduction in any medium, provided the work is properly cited. 